\title{
Preparing Future Skills and Professional Communication Skills
}

\author{
Eka Dian Savitri, Ni Gusti Made Rai, and Aurelius Ratu \\ Departement of Development Studies, Institut Teknologi Sepuluh Nopember, Surabaya, Indonesia. \\ e-mail: eka.dian@its.ac.id
}

\begin{abstract}
Some literature studies showed that to get a better career in the contemporary work environment, students need to develop critical thinking skills, problem solving, emotional intelligence, teamwork, and communication. There is, however, in fact a doubt that educational institutions do not sufficiently provide the needed skills to cope with work competition. While World Economic Forum 2020 indicated about 15 skills that have increasing demand in workplace, educational institutions show slow responses toward the demand which means that students might obtain these skills in the context of non-academic learning process. Some of these skills such as critical thinking analysis, complex problems solving, and analytical thinking and innovation has become the prerequisite skills for the today career. Thus, students need to prepare themselves by increasing the knowledge and skills needed in the future. In virtue of the work demands, educational institutions need to design their curriculum in accordance with the work environment as to be able in bridging a transition from school to work environment.
\end{abstract}

Keywords-Future Skill, Professional Communication Skill, Career.

\section{I.INTRODUCTION}

$\mathrm{I}^{\mathrm{n}}$ $\mathrm{n}$ the fast-changing world and job demands based on competence, several studies conducted on career adaptability, employability and career resilience have become important and essential topics in current society. This can be observed in studies that discuss the transition from school to a satisfying life or the effect of societal change on one's career adaptability [1]. With the increasing importance of this concept and the role of education in preparing students to be ready for work, several subsequent studies have tried to understand the influence of the educational environment as a preparation stage for work [2]-[5] and some even add an entrepreneurial process to adapt academic procedures and curricula to ensure the best possible results in the workplace [6], [7].

Recognizing that the educational environment has an important influence on career adaptability, there are currently emerging strategies intended to be work-oriented systems [8]. In fact, there seems to be a tendency in the educational process itself to shift from a mindset of looking for work to a mindset of creating and providing employment.

Over the last few years, entrepreneurship education has entered the student learning process. It is, however, uncertain whether this educational process makes it easier for students to work successfully or to make their careers flourish. Thus, measures of success in the workplace have been a field of interesting topic for the practitioners or the researchers who observed some relationship between personality traits for career development [9], [10] or the effect of the learning process for work-readiness [11], [12].

The educational context in which 'real world' interactions are experienced by students should prepare students for a much more holistic viewpoint to develop their careers. In expecting job-ready graduates, learning process in education setting must be adaptable to the changing world of work. On another side, it must also be admitted that education does not guarantee success. Students need to develop new skills in several aspects to be able to keep up with the demands of the workplace. This paper is an effort to offer practitioners a framework for assessing how the best strategy to help students deal with career transitions and changes during their academic process and implement appropriate interventions within the process.

\section{PREPARE FOR THE CAREER}

Most students believe that the education provision they have is sufficient to lead to a successful career. Students, however, often worried about their future in the world of work since there are certain conditions that must be met in applying for a job. This situation shows that there might be some specific skills to improve to be better prepared in searching for a job. In addition to the existing pandemic situation, the number of college graduates seem to have a little chance to get a better job. This fact makes it necessary for every student to have sufficient insight to be counted as potential employees or qualified professionals.

In psychological point of view, work readiness is considered a part of employability characteristics by which a person needs to manage it well. With that character, individuals are expected to be more adaptable to work in different environment than those who have not such a character. Besides, it may reduce the waiting period in finding certain jobs [13]. Thus, students are ready when they enter into a workplace wherein social interaction and communication among the others take place.

Strictly speaking, employability is the capability on how a person understands his/her personal attributes that make $\mathrm{him} /$ her satisfied in life and successful at work [14]. There is no doubt that "future skills", "personality development", "professional communication", and "organizational communication" are some of prerequisite abilities to gain during academic process and to be expected as leading attributes of each graduates before they enter into workplace.

\section{FUTURE SKILL}

Trends in the world of work indicate that there is a shift in understanding skills needed and prepared for the postgraduation period. According to James Hekman, skills are composed of two aspects that of cognitive and non-cognitive aspects [15]. Cognitive skills are related to thinking skills such as knowledge and understanding, and non-cognitive skills are consisting of personality and social emotional behavior. 
Current work activities increasingly require skills in critical thinking, problem solving, emotional intelligence, and teamwork. Though these skills in the late ten years have been a dominant discussion among educators and practitioners, development in special field of works push every educational institution to incorporate some sort of learning process which is entrepreneurship. In the first sight, it is not primarily intended to create an entrepreneur, but it seeks to explore deeper into productive thinking. It is expected then students know how to manage themselves, to be confident as same as they work as an employee.

There are three aspect that get more attention during the change from an industrial society to a knowledge-based society, namely: personality traits, life themes, and career adaptability. First, personality traits mean how self-concept can help someone in adjusting personality structure to fit their objective world. The second aspect is an attempt to implement self-concept through work as personality manifestation. An essential thing of this aspect is a continuing process of improving the match between the self and situation. The third aspect is adaptability which understands one's behavior, attitude, and competence are always in the matching process. These three aspects are the response to a changing self and situations.

On the other hand, companies estimate that about $40 \%$ of workers will need training or new skills [16]. Several skills are of concern in the future until 2020, according to WEF 2020: (1) analytical thinking and innovation, (2) active learning and learning strategies, (3) complex thinking, (4) critical thinking and analysis; (5) creative and initiative, (6) leadership and social influence, (7) use of technology, (8) design and programming technology, (9) resilience, stress tolerance and flexibility, (10) problem solving and ideas, (11) ) emotional intelligence, (12) customer experience, (13) service orientation, (14) system analysis and evaluation, (15) persuasion and negotiation. Based on data from Coursera, the skills which need to be improved are those that match the existing type of work but also identify the necessary emphasis on self-development and self-management [16].

\section{PROFESSIONAL COMMUNICATION}

In the face of work complexities, professional communication skills get more attention as goals of the company can be successfully achieved by solid teamwork. Professional communication is often called organizational communication. Good organizational communication involves many other abilities in supporting communication success. Two types of communication skills that must be acquired in establishing professional communication effectively which are intrapersonal and interpersonal communication. Intrapersonal communication refers to a communication with oneself which involves cognitive behaviour and internal communication, for example, interpretation of other people messages, determining goals and strategies, self-discovery, and self-delusion [17]. Meanwhile, interpersonal communication refers to a communication to other parties or groups. Since the ability to communicate with others is influenced by psychological/mental factors, perceptions, emotions, reasoning abilities, and the values/culture factor, the success of interpersonal communication can be achieved.
The ability to communicate with other parties in work environment generally covers three important factors, namely team work, leadership, and problem solving [18]. First, teamwork means that women and men speak with different communication styles as women are supposed to frequently ask sorry rather than men [19], more nurturing relationships [20], considerate and respond more quickly to negative emotions [21]. Second, communication is predisposed by context and culture as well such as linguistic expression; pay attention to the context of information and communication tools; consider social relations such as peer, senior-junior, superior-subordinate relationships; and considering culture, norms and ethics. Third, effective communication needs to avoid emotional responses, especially negative emotions. Therefore, we need to practice intrapersonal communication skills to affirm positive messages and values by using positive words in communicating.

The results of a survey conducted by The Harris Poll [22] to workers in New York showed that effective communication was instrumental in establishing a good company reputation. The report confirms that managers act as main communicators for employees. However, only $33 \%$ of managers strongly agree that they are the main communicators of employees, and only $47 \%$ strongly agree that they are well trained and ready to be the company's main communicators to employees. This means that most leaders do not have the ability and self-confidence as effective communicators in the company/organization. To the recent years, communication may strengthen the leadership position within an organization or a company. In this context, leadership means an ability to direct, delegate, motivate, influence, and inspire others to achieve organizational/company goals. For this very reason, organizational success depends on effective communication skills which make every person understand their contribution to the company and vice versa. According to Barret [23], There are three levels of communication competence that a leader must have as seen in Figure 1.

The first is communication skill in the context of selfcapability such as writing skills, speaking skills, and strategic abilities. The second level is managerial communication which means an ability to manage individuals, groups, organizations, community events. This level relates closely to emotional intelligence, cultural literacy, mentoring, listening, and meetings. And the third level is corporate communication which means an ability to communicate with a broader and more complex level. In the third level, the communication style is to represent the image of the company/organization. In other words, leadership bring image bearing of the company into oneself. He or she is no longer a person in individual form but referred as third party, as an institution. The leadership on each level has an impact partly or wholly on the success of the organization itself. Furthermore, one of the results of research in the context of companies in Indonesia (MNC Group) regarding the level of communication in organizations requires the development of a distinctive strategy according to organizational characteristics [25].

Leadership communication skill include strategies to solve problems or resolve conflicts in organizations as well. A leader both in groups and individually must have problem solving skills as well as resolve conflicts in the workplace. 


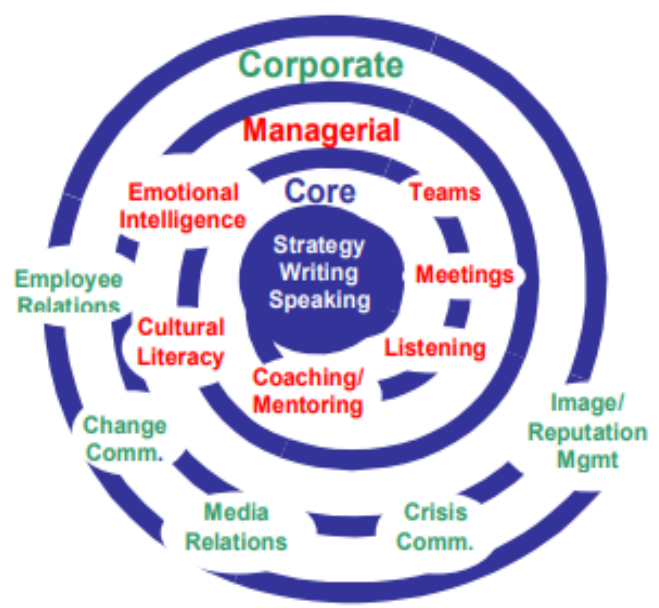

Figure 1. The leadership communication framework

What we need to do are (1) try to solve the problem as soon as possible according to the priority and the team's expectations [18] so as not to make new problems. Though we need promptness in solving problems, we should not be impulsive (instinct). The ability to solve problems quickly and using instinct requires a lot of previous experience. (2) Resolving problems in the workplace should be based on clarification of appropriate information from colleagues or other employees. (3) To get the right information, we need to explore the information while listening empathetically. (4) Responding to problems or conflicts by placing ourselves in the position of others' view, understanding our audience, choosing the right diction, intonation, and language style in communicating.

\section{CONCLUSION}

In the future, the challenges in the world of work are getting higher due to the changing trend in types of work. Meanwhile, student competencies developed by educational institutions are deemed unsuitable or even incompatible with the needs of the industrial world [15]. Students need to prepare themselves by increasing the knowledge and skills needed in the future, even though these additional skills must be obtained outside of educational institutions. Efforts to improve skills such as personality development and professional communication will help students achieve career success. Meanwhile, educational institutions should immediately design their curriculum according to the skills needs of the world of work in the future.

\section{REFERENCES}

[1] Kobus Maree, "The Psychology of Career Adaptability, Career Resilience, and Employability: A Broad Overview," in Psychology of Career Adaptability, Employability and Resilience, 1st ed., Kobus Maree, Ed. Switzerland: Springer International Publishing, 2017, pp. 3-11.

[2] M. L. Savickas, E. J. Porfeli, T. L. Hilton, and S. Savickas, "The student career construction inventory," J. Vocat. Behav., vol. 106,, pp. 138-152, Jun. 2018.
[3] W. Fang, Y. Zhang, J. Mei, X. Chai, and X. Fan, "Relationships between optimism, educational environment, career adaptability and career motivation in nursing undergraduates: a cross-sectional study," Nurse Educ. Today, vol. 68, pp. 33-39, Sep. 2018.

[4] J. Pan et al., "The interplay of proactive personality and internship quality in chinese university graduates' job search success: The role of career adaptability," J. Vocat. Behav., vol. 109, pp. 14-26, Dec. 2018.

[5] D. Spanjaard, T. Hall, and N. Stegemann, "Experiential learning: helping students to become 'career-ready,"' Australas. Mark. J., vol 26, no. 2, pp. 163-171, May. 2018.

[6] R. Badri and N. Hachicha, "Entrepreneurship education and its impact on students' intention to start up: a sample case study of students from two tunisian universities," Int. J. Manag. Educ., vol. 17, no. 2, pp. 182-190, Jul. 2019.

[7] I. Šverko and T. Babarović, "Applying career construction model of adaptation to career transition in adolescence: a two-study paper," $J$. Vocat. Behav., vol. 111, pp. 59-73, Apr. 2019.

[8] D. Meng, X. Li, and K. Rong, "Industry-to-university knowledge transfer in ecosystem-based academic entrepreneurship: case study of automotive dynamics \& control group in tsinghua university," Technol. Forecast. Soc. Change, vol. 141, pp. 249-262, Apr. 2019.

[9] M. Parmentier, T. Pirsoul, and F. Nils, "Examining the impact of emotional intelligence on career adaptability: A two-wave crosslagged study," Pers. Individ. Dif., no. May, pp. 0-1, Dec. 2019.

[10] J. Wen, S. Huang, and P. Hou, "Emotional intelligence, emotional labor, perceived organizational support, and job satisfaction: A moderated mediation model," Int. J. Hosp. Manag., vol. 81, no. January, pp. 120-130, Aug. 2019.

[11] T. Baum, "A changing world of work. What can we learn from the service sector about employing Millennials (and Gen Z)?," Organ. Dyn., 2019.

[12] A. Gregory and J. Fawkes, "A global capability framework: Reframing public relations for a changing world," Public Relat. Rev. vol. 45, no. 3, p. 101781, Sep. 2019

[13] A. L. Kadiyono and R. A. Sulistiobudi, "Peningkatan graduate employability melalui career development training pada mahasiswa," J. Pengabdi. Kpd. Masy., vol. 2, no. 12, p. 72-78, Dec. 2018.

[14] L. D. Pool and P. Sewell, "The key to employability: developing a practical model of graduate employability," Educ. Train., vol. 49, no. 4, pp. 277-289, 2007.

[15] W. Cunningham and P. Villaseñor, "Employer voices, employer demands, and implications for public skills development policy," Policy Res. Work. Pap., no. February, p. paper 7582, 2014.

[16] WEF, "The Future of Jobs Report 2020," Geneva, 2020.

[17] M. Allen, "The SAGE Encyclopedia of Communication Research Methods." Thousand Oaks, California, 2017.

[18] P. Berry, "Communication skills for women in the world of corporate business: getting it right and moving up!," Am. J. Bus. Educ., vol. 3, no. 1, pp. 83-90, 2010.

[19] T. Walfisch, D. Van Dijk, and R. Kark, "Do you really expect me to apologize? the impact of status and gender on the effectiveness of an apology in the workplace," J. Appl. Soc. Psychol., vol. 43, no. 7, pp. 1446-1458, 2013.

[20] B. G. Ogolsky and J. R. Bowers, "A meta-analytic review of relationship maintenance and its correlates," J. Soc. Pers. Relat., vol. 30, no. 3, pp. 343-367, 2013.

[21] Y. Deng, L. Chang, M. Yang, M. Huo, and R. Zhou, "Gender differences in emotional response: Inconsistency between experience and expressivity," PLoS One, vol. 11, no. 6, pp. 1-12, 2016.

[22] The Harris Poll, "Effective Employee Communications Fosters Corporate Reputation," New York, 2015.

[23] D. J. Barrett, Leadership Communication, 4th ed. New York: McGraw-Hill, 2014.

[24] D. Barrett, Leadership Communication: A Communication Approach for Senior-Level Managers. Handbook of Business Strategy Emerald Group Publishing, 2006.

[25] A. Mulyana, F. Hamid, S. Mansur, and S. Susilawati, "Kepemimpinan efektif melalui kompetensi komunikasi di media nusantara citra group," J. Kaji. Komun., vol. 7, no. 2, p. 184, 2019 